\title{
A Survey of Dangers Experienced by Mothers and Families of Infants Aged 3 - 4 Months during Ablution and Bathing
}

\author{
Sachi Chikazawa',2, Ayako Sasaki ${ }^{1}$ \\ ${ }^{1}$ Faculty of Nursing, School of Nursing, Osaka Medical and Pharmaceutical University, Osaka, Japan \\ ${ }^{2}$ Doctoral Program, Graduate School of Nursing, Osaka Medical and Pharmaceutical University, Osaka, Japan \\ Email: sachi.chikazawa@ompu.ac.jp
}

How to cite this paper: Chikazawa, S. and Sasaki, A. (2021) A Survey of Dangers Experienced by Mothers and Families of Infants Aged 3 - 4 Months during Ablution and Bathing. Health, 13, 1242-1269. https://doi.org/10.4236/health.2021.1311091

Received: October 16, 2021

Accepted: November 13, 2021

Published: November 16, 2021

Copyright $\odot 2021$ by author(s) and Scientific Research Publishing Inc. This work is licensed under the Creative Commons Attribution International License (CC BY 4.0).

http://creativecommons.org/licenses/by/4.0/

\begin{abstract}
Purpose: The purpose of this study is to explore the dangers experienced by mothers and families of infants aged 3 - 4 months in Japan during ablution and bathing. Method: We distributed an anonymous, self-reported questionnaire at infants' 3 - 4-month health checkup, which was collected via postal service. 170 valid responses were received and formed our sample data. Descriptive statistical analysis was performed for each category surveyed. Inferential statistics were used to compare the dangerous incidents experienced with regard to differences between primi/multipara and the presence/absence of guidance concerning such incidents. This study was approved by the research ethics committees of the affiliated university. Results: $60.0 \%$ of mothers and families experienced dangers while washing their infant in a baby tub or similar apparatus (ablution), and $64.9 \%$ did while bathing their infant in the normal bath. For ablution, the most common dangers were, in order, nearly dropping the infant in the water and nearly getting soap suds in the mouth. For bathing, these were nearly getting soap suds in the mouth, near submersion of the face, and nearly dropping the infant in the water. The percentage of mothers and families who did not receive instruction regarding potential dangers and their prevention was $55.9 \%$ for ablution and $81.8 \%$ for bathing. Conclusion: This study revealed the dangers experienced by mothers and families of infants aged 3 - 4 months in Japan during ablution and bathing. Further consideration into the prevention of these dangers is necessary.
\end{abstract}

\section{Keywords}

Ablution, Bathing, Incidents, Experience, Infants 


\section{Introduction}

Caring for an infant involves a variety of elements, including feeding, putting the infant to sleep, changing diapers, and bathing. Bathing in particular is a multifaceted process involving a series of actions, including changing clothes, washing, keeping hold of the infant, and moisture management. Moreover, in Japan bathing space is often limited, and the many independent actions involved demand considerable dexterity. It is also necessary to monitor the infant's condition and adapt bathing methods accordingly. For mothers and families lacking adequate knowledge and practice, safe and comfortable bathing can be a difficult undertaking.

Bathing and washing are important for infant hygiene, observation of the state of the body, improvement of metabolism, establishing a life rhythm, and parent-child intimacy. In recent years, the length of post-birth hospital stays in Japan have shortened [1], and wait-to-bathe and delayed bathing policies (known as "dry technique" in Japan), in which blood, amniotic fluid, and meconium are wiped off the newborn while leaving the vernix as undisturbed as possible, have increased in popularity [2]. Due to this, there are fewer opportunities to wash the infant in the hospital, and many mothers bring their babies home having never practiced washing them. This situation has made it difficult to acquire these skills during a standard hospital visit. In Japan, the standard advice is to wash the baby in a special baby tub until its one-month checkup, after which it may be bathed in the family bath. However, little specific instruction as to actual technique is given [3].

As there is an element of danger when bathing, unexpected accidents are known to occur. In the current state of Japanese society, parents can hardly avoid situations in which they must bathe their infant without help or in which multiple children are in need of care at the same time. Inexperience and impaired constitution or judgement due to fatigue are also among the many factors which lead to accidents. The majority of drowning incidents occur in the family bath [4] [5] [6], and have occurred during moments of insufficient supervision, even when a family member was present [4]. There is also a continuous stream of new baby care products coming to the market. Drowning incidents involving bathing equipment were among the most common types of drowning incidents reported [7]. There were also fatal drownings among the reported cases [8].

Underreporting of incidents also obfuscates bathtime dangers. According to Heinrich's triangle, 300 minor incidents occur for every one major injury. It can be assumed that a large number of families experience close calls in the course of their daily bathing routine that go unreported.

Existing research concerning infant washing and bathing has evaluated newborn care and revealed facts about the instruction of mothers and baby skin care issues from the time of delivery to discharge from the hospital. However, no research has touched on the troubles families have in relation to bathing their infants at home [9]. The results of this study show that over half of subject moth- 
ers had bathing-related troubles, $36.8 \%$ of primipara and $17.1 \%$ of multipara felt a sense of danger associated with bathing. Subjects wished for more support and safety tips from nurses concerning bathing [3]. Furthermore, although there were reports of fatal accidents, the dangers actually experienced by mothers and families were unclear [10].

The state of local communities and parenting are changing, and insufficient consideration has been given to guidance on ablution and bathing. On top of this, the dangers experienced by families are ambiguous. It is a problem that measures are not being taken despite the fact that dangers can be expected to arise from the lack of instruction in present-day Japan.

From the above points, we have concluded that measures must be taken to assist mothers and their families in safely and confidently bathing their newborns at home. With this in mind, we conducted this study with the purpose of exploring the situation in Japan regarding the risks related to ablution and bathing experienced by families with infants aged $3-4$ months.

\section{Methods}

1) Terms

a) Washing/Ablution: Sanitary care using a specialized baby tub, with warm or lukewarm water, and the series of related actions including preparation, changing, washing, holding the body, and post-washing care.

b) Bathing: Sanitary care which takes place in the family bath, often with hot water, as a part of the normal daily routine and the series of related actions including preparation, changing, washing, holding the body, and post-washing care.

c) Dangers: Accidents during ablution or bathing which threaten the life or health of the infant, as well as close calls which did not have a lasting effect on the infant's life or health.

2) Study Design \& Survey Period

a) Study Design

Fact-finding survey

b) Survey Period

June 9, 2020-August 24, 2020.

3) Subjects

Mothers who brought their infants for their 3 - 4-month health checkup at a health center in city A and had experience with both bathing and ablution. Using $\mathrm{G} *$ Power, the minimum required sample size to ensure an effect size of 0.5 , given $\alpha=0.05$ and a power of 0.8 , was calculated to be 134 subjects.

4) Method of Data Collection

With the advance permission of a health center located in Osaka Prefecture, researchers verbally requested participation following 3 - 4-month health checkups. Mothers who gave consent received an anonymous, self-reported questionnaire, which was collected via postal service. 


\section{5) Contents of Survey}

The survey contained 20 questions in total, some of which were prepared for this study with reference to prior research [9]-[15]. Pretesting was conducted on four mothers with children aged 3 - 4 months.

6) Method of Analysis \& Evaluation

Each item of the self-reported responses was analyzed using the statistics software SPSS version 27.0. Additionally, inferential statistics was used to compare the differences between primipara/multipara and the presence/lack of instruction pertaining to experienced dangers. Inferential statistics were verified using the $\chi^{2}$ test or Fisher's exact test, with a significance level of less than $5 \%$.

7) Ethical Considerations

This study was conducted with the approval of the Osaka Medical and Pharmaceutical University Ethics Committee (Approval code: Nursing-142 2862, approved January 10, 2020). With the advance permission of a health center located in Osaka Prefecture, questionnaires and explanatory materials were distributed to mothers following their infants' 3 - 4-month health checkups. Consent was given in writing upon submission of the questionnaire. Subjects were informed of the study's title, the names of the involved research organizations, the name of the principal investigator, the purpose of the study, the method and term of the study, the reason they were selected to participate, that the benefit of their participation would be their contribution to the field of nursing and that there would be no direct profit or compensation for their cooperation, that personal information would be anonymized and coded in such a way that such information would not be personally identifiable, that anonymity would be maintained in any published data, the method of storage and disposal of personal information, the circumstances involving conflicts of interest with the research, and the availability of the researchers or related parties for consultation. The content of the questionnaire was carefully selected in order to minimize the burden on participants.

\section{Results}

1) Questionnaire collection rate

Questionnaires were given to 318 individuals, and 170 responses were received (collection rate of 53.4\%). For questionnaires which contained incomplete or inappropriate answers, those answers were classified as "no response" during the analysis.

2) Subject characteristics (Tables 1-3)

Table 1 shows the number and age of children in each household, Table 2 shows the parents' employment status, and Table 3 shows the parents' bathing habits.

77 subjects (45.3\%) were on their second child or later, while 93 were on their first (54.7\%). The 30 - 34 age group was the most common both for mothers and fathers, with 67 mothers $(40.6 \%)$ and 65 fathers $(39.2 \%)$ in that range. 13 mothers (7.6\%) and 157 fathers (92.4\%) were working. 89 mothers $(52.4 \%)$ were on 
Table 1. Number of children and age of older children in household.

\begin{tabular}{cccc}
\hline & & $\#$ & $\%$ \\
\hline $\begin{array}{c}\text { Number of Children } \\
(\mathrm{n}=170)\end{array}$ & Second child or later & 77 & 45.3 \\
& First child & 93 & 54.7 \\
\hline & 1 year & 3 & 3.9 \\
Age of Older Children & 2 years & 20 & 26.0 \\
$(\mathrm{n}=77)$ & 3 years & 22 & 28.6 \\
$($ multiple response $)$ & 4 years & 22 & 28.6 \\
& 5 years & 10 & 13.0 \\
& 6 years & 15 & 19.5 \\
& 7 y years & 12 & 15.6 \\
& No response & 3 & 3.9 \\
\hline
\end{tabular}

Table 2. Parents' employment Status $(n=170)$.

\begin{tabular}{cccccc}
\hline \multicolumn{6}{c}{ Number (\%) } \\
\hline & Employed & Unemployed & On childcare leave & Other & No response \\
\hline Mothers & $13(7.6)$ & $58(34.1)$ & $89(52.4)$ & $2(1.2)$ & $8(4.7)$ \\
Fathers & $157(92.4)$ & $3(1.8)$ & $3(1.8)$ & $1(0.6)$ & $6(3.5)$ \\
\hline
\end{tabular}

Table 3. Parents' bathing habits $(n=170)$.

\begin{tabular}{lcccccc}
\hline \multicolumn{7}{c}{ Number (\%) } \\
\hline $\begin{array}{c}\text { Bath } \\
\text { (daily) }\end{array}$ & $\begin{array}{c}\text { Shower } \\
\text { only }\end{array}$ & $\begin{array}{c}\text { Shower usually, } \\
\text { with } \\
\text { occasional bath }\end{array}$ & $\begin{array}{c}\text { Shower in } \\
\text { summer, } \\
\text { bath in winter }\end{array}$ & Other & $\begin{array}{c}\text { No } \\
\text { response }\end{array}$ \\
\hline Mothers & $91(53.5)$ & $17(10.0)$ & $28(16.5)$ & $25(14.7)$ & $2(1.2)$ & $7(4.1)$ \\
Fathers & $81(47.6)$ & $18(10.6)$ & $33(19.4)$ & $28(16.5)$ & $4(2.4)$ & $6(3.5)$
\end{tabular}

maternity leave, and 3 fathers $(1.8 \%)$ on paternity leave. The majority of mothers $(116,68.2 \%)$ gave birth in hospitals. Regarding bathing and showering habits, bathing in a tub was most common, with 91 mothers (53.5\%) and 81 fathers (47.6\%) taking a bath every day.

3) The state of ablution

a) Washing routine (Table 4)

Table 4 shows the breakdown of subjects' washing routines for their children.

128 mothers $(75.3 \%)$ and 35 fathers $(20.6 \%)$ were the main parent to wash their infant. 105 fathers (61.8\%) and 72 mothers (42.4\%) played an assisting role in ablution.

The most common cleaning agent used for ablution was foamy soap, with 140 subjects $(82.4 \%)$. The most common washing implement was the hands (140 
Table 4. State of children's ablution $(n=170)$.

\begin{tabular}{|c|c|c|c|}
\hline & & $\#$ & $\%$ \\
\hline \multirow{7}{*}{ Primary washer } & Mother & 128 & 75.3 \\
\hline & Father & 35 & 20.6 \\
\hline & Maternal grandmother & 10 & 5.9 \\
\hline & Paternal grandmother & 1 & 0.6 \\
\hline & Sibling & 1 & 0.6 \\
\hline & Other & 2 & 1.2 \\
\hline & No response & 1 & 0.6 \\
\hline \multirow{9}{*}{$\begin{array}{l}\text { Assists with washing } \\
\text { (multiple response) }\end{array}$} & Mother & 44 & 25.9 \\
\hline & Father & 105 & 61.8 \\
\hline & Maternal grandmother & 72 & 42.4 \\
\hline & Maternal grandfather & 15 & 8.8 \\
\hline & Paternal grandmother & 8 & 4.7 \\
\hline & Sibling & 14 & 8.2 \\
\hline & None & 8 & 4.7 \\
\hline & Other & 6 & 3.5 \\
\hline & No response & 2 & 1.2 \\
\hline \multirow{5}{*}{$\begin{array}{c}\text { Cleansers used } \\
\text { (multiple response) }\end{array}$} & Solid soap & 25 & 14.7 \\
\hline & Liquid soap & 8 & 4.7 \\
\hline & Foam soap & 140 & 82.4 \\
\hline & Body wash & 27 & 15.9 \\
\hline & No response & 1 & 0.6 \\
\hline \multirow{4}{*}{$\begin{array}{l}\text { Washing instruments } \\
\text { (multiple response) }\end{array}$} & Hands & 140 & 82.4 \\
\hline & Gauze & 134 & 78.8 \\
\hline & Towel & 5 & 2.9 \\
\hline & No response & 1 & 0.6 \\
\hline \multirow{3}{*}{$\begin{array}{l}\text { Rinsing method } \\
\text { (multiple response) }\end{array}$} & Shower & 71 & 41.8 \\
\hline & Pouring water & 131 & 77.1 \\
\hline & Other & 5 & 2.9 \\
\hline
\end{tabular}

subjects, $82.4 \%$ ), followed by gauze (134 subjects, $78.8 \%)$. 131 subjects (77.1\%) responded that they rinsed their infant by pouring water over it, and $71(41.8 \%)$ rinsed with the shower head.

b) Dangers experienced during ablution (Table 5, Figures 1-4)

Table 5 shows whether subjects experienced incidents or not during ablution. Figure 1 shows what dangers were experienced, Figure 2 shows the situations in 
Table 5. Experienced incidents during ablution $(n=170)$.

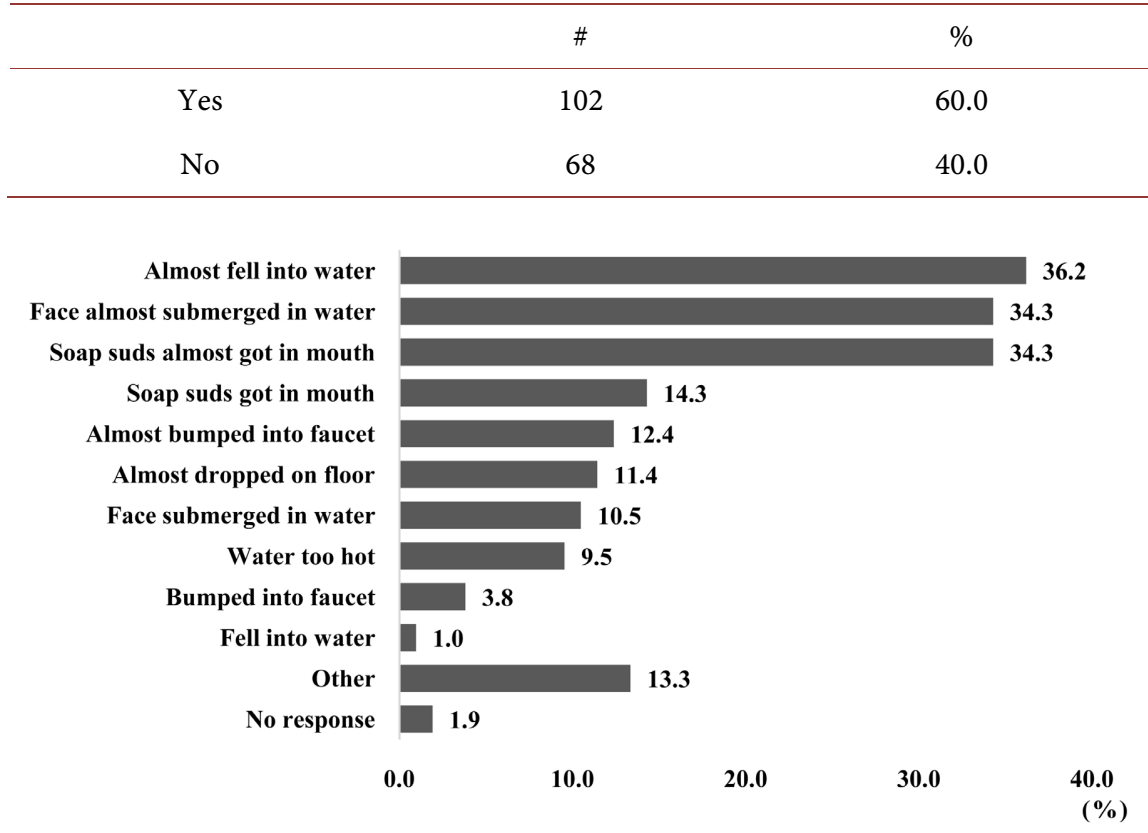

Figure 1. Incidents experienced during ablution $(\mathrm{n}=102)$ (Multiple response).

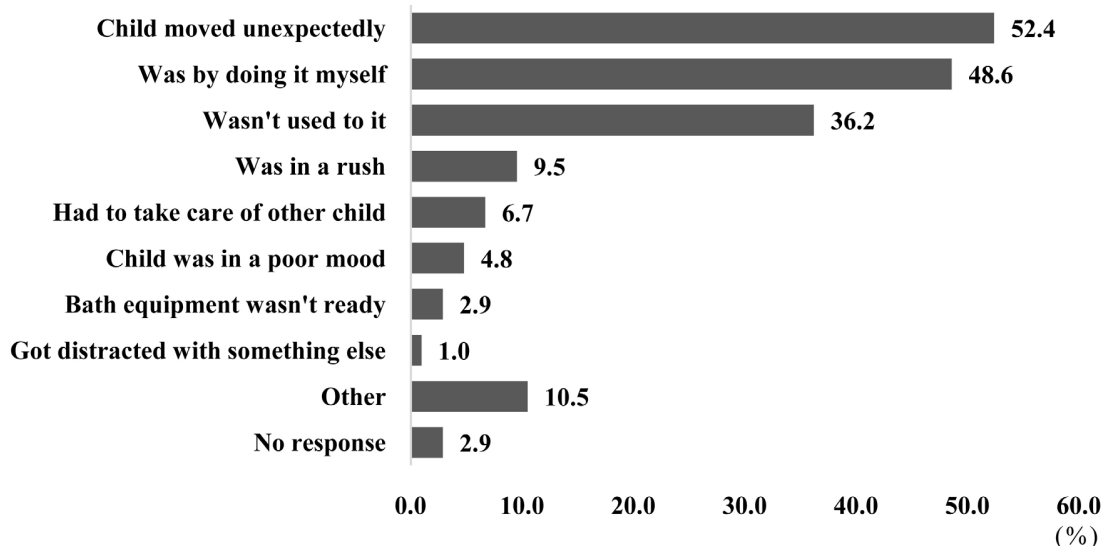

Figure 2. Situations when incidents occurred during ablution $(\mathrm{n}=102)$ (Multiple response).

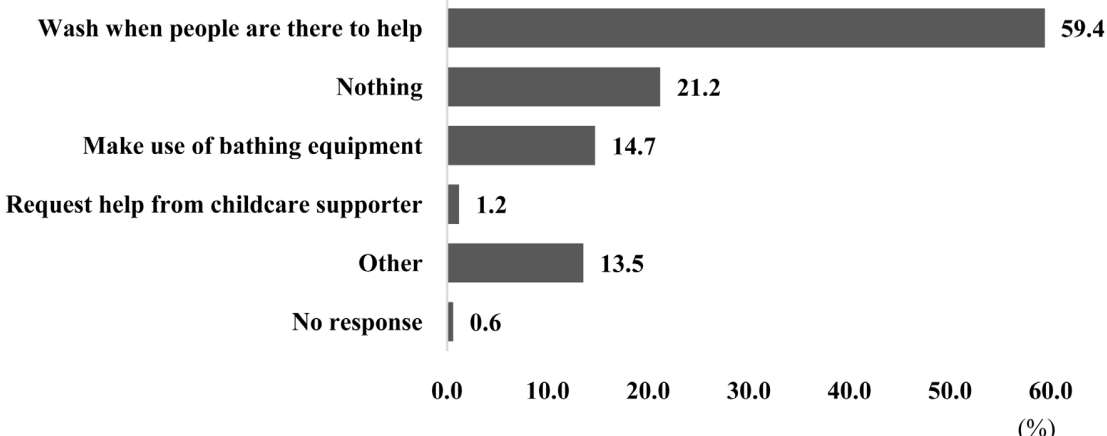

Figure 3. Measures taken to prevent incidents during ablution $(\mathrm{n}=170)$ (Multiple response). 
which incidents occurred, and Figure 3 shows what measures were taken to prevent incidents.

102 subjects $(60.0 \%)$ responded that they had experienced dangers during ablution. Among the mothers and families who experienced incidents, near drops into the water were the most common $(n=38,36.2 \%)$, followed by near-submersion of the face and soap suds in the mouth $(\mathrm{n}=36,34.3 \%)$. The most common situations in which dangers were experienced were the child moving unexpectedly ( $\mathrm{n}=55,52.4 \%)$, washing the child by oneself $(\mathrm{n}=51,48.6 \%)$, and being unfamiliar with the process $(n=38,36.2 \%)$.

The most common responses concerning the measures taken to prevent incidents were: washing when someone was available to help $(\mathrm{n}=101,59.4 \%)$, no measures taken $(\mathrm{n}=36,21.2 \%)$, and using equipment (bath seat, etc.) $(\mathrm{n}=25$, 14.7\%).

c) The state of instruction (Table 6)

Table 6 shows the state of instruction regarding the dangers that can occur during ablution and the prevention of such dangers.

95 mothers and families (55.9\%) had not received instruction regarding the possible dangers that can occur during ablution or the prevention of such dangers. Among the 75 respondents who had received instruction, the content of the instruction included what kinds of incidents can happen $(\mathrm{n}=61,81.3 \%)$ and prevention methods $(\mathrm{n}=45,60.0 \%)$. The most common settings in which instruction was received were: during the hospital stay after childbirth $(\mathrm{n}=70$, 93.3\%) and in parenting classes $(n=20,26.7 \%)$.

Table 6. State of instruction concerning possible ablution-related incidents.

\begin{tabular}{|c|c|c|c|}
\hline & & $\#$ & $\%$ \\
\hline \multirow{3}{*}{$\begin{array}{c}\text { Content } \\
(\mathrm{n}=75) \\
\text { (multiple response) }\end{array}$} & What kinds of incidents can happen & 61 & 81.3 \\
\hline & Prevention methods & 45 & 60.0 \\
\hline & Other & 3 & 4.0 \\
\hline \multirow{4}{*}{$\begin{array}{l}\text { Place of instruction } \\
\qquad(\mathrm{n}=75) \\
\text { (multiple response) }\end{array}$} & Maternity classes & 13 & 17.3 \\
\hline & Parenting classes & 20 & 26.7 \\
\hline & During hospital stay after childbirth & 70 & 93.3 \\
\hline & Home visit & 1 & 1.3 \\
\hline \multirow{6}{*}{$\begin{array}{l}\text { Source of information } \\
\qquad(\mathrm{n}=170) \\
\text { (multiple response) }\end{array}$} & Internet & 30 & 17.6 \\
\hline & Maternity magazine/parenting materials & 44 & 25.9 \\
\hline & Nurse, midwife, or public health nurse & 114 & 67.1 \\
\hline & No information received & 28 & 16.5 \\
\hline & Other & 11 & 6.5 \\
\hline & No response & 3 & 1.8 \\
\hline
\end{tabular}


The most common sources of information concerning ablution-related dangers were: from a nurse/midwife/public health nurse $(n=114,67.1 \%)$ and from maternity or parenting magazines ( $\mathrm{n}=44,25.9 \%)$.

d) Comparison of experienced dangers based on number of children and presence of instruction (Table 7 and Table 8)

Table 7 compares subjects by the number of children they have while Table 8 compares subjects based on whether they received instruction or not.

When comparing situations by the number of children, more subjects with a single child selected "wasn't used to it" than those with multiple children, while significantly more subjects with multiple children selected "taking care of other children" than those with a single child. No significant differences were seen between subjects who received instruction and those who did not.

e) Comparison of prevention measures based on number of children and presence of instruction (Table 9 and Table 10)

Table 9 and Table 10 show the measures taken to prevent accidents. Table 9 compares subjects by the number of children they have while Table 10 compares subjects based on whether they received instruction or not.

When comparing measures by the number of children, significantly more subjects with multiple children selected "none" than those with a single child, while more subjects with a single child selected "give bath when people are there to help" than those with multiple children. No significant differences were seen between subjects who received instruction and those who did not.

4) Opinions and requests for nurses concerning ablution

49 subjects (28.8\%) submitted freeform responses containing their opinion and requests for nursing professionals concerning ablution.

Categories of opinions and requests for nursing professionals are listed below, with specific examples of each in parentheses: ablution technique (how to wash), concrete examples of dangers ("I want to know more about close calls."), methods of dealing with accidents when they occur (what to do when water or soap get in the eyes, ears, or mouth), methods and caution points for washing an infant by oneself (tips for washing my baby by myself), methods and caution points for washing at home ("When they told me how to wash my baby at the hospital they had special equipment and it went smoothly, but when I actually got home it didn't go well and I had trouble."), using bathing equipment ("I wish they told me specifically how to use bath accessories."), and the timing/frequency of instruction ("I watched the nurse wash my baby but I only got to try it once for myself. I would have liked at least one more chance.").

Families with multiple children expressed opinions in the categories of ablution technique, concrete examples of dangers, methods and caution points for washing at home, and using bathing equipment.

Families with a single child expressed opinions in the categories of washing technique, concrete examples of dangers, how to deal with accidents when they occur, using bathing equipment, and the timing/frequency of instruction.

5) The state of bathing 
Table 7. Comparison of incidents experienced during ablution and situations between Primipara and Multipara.

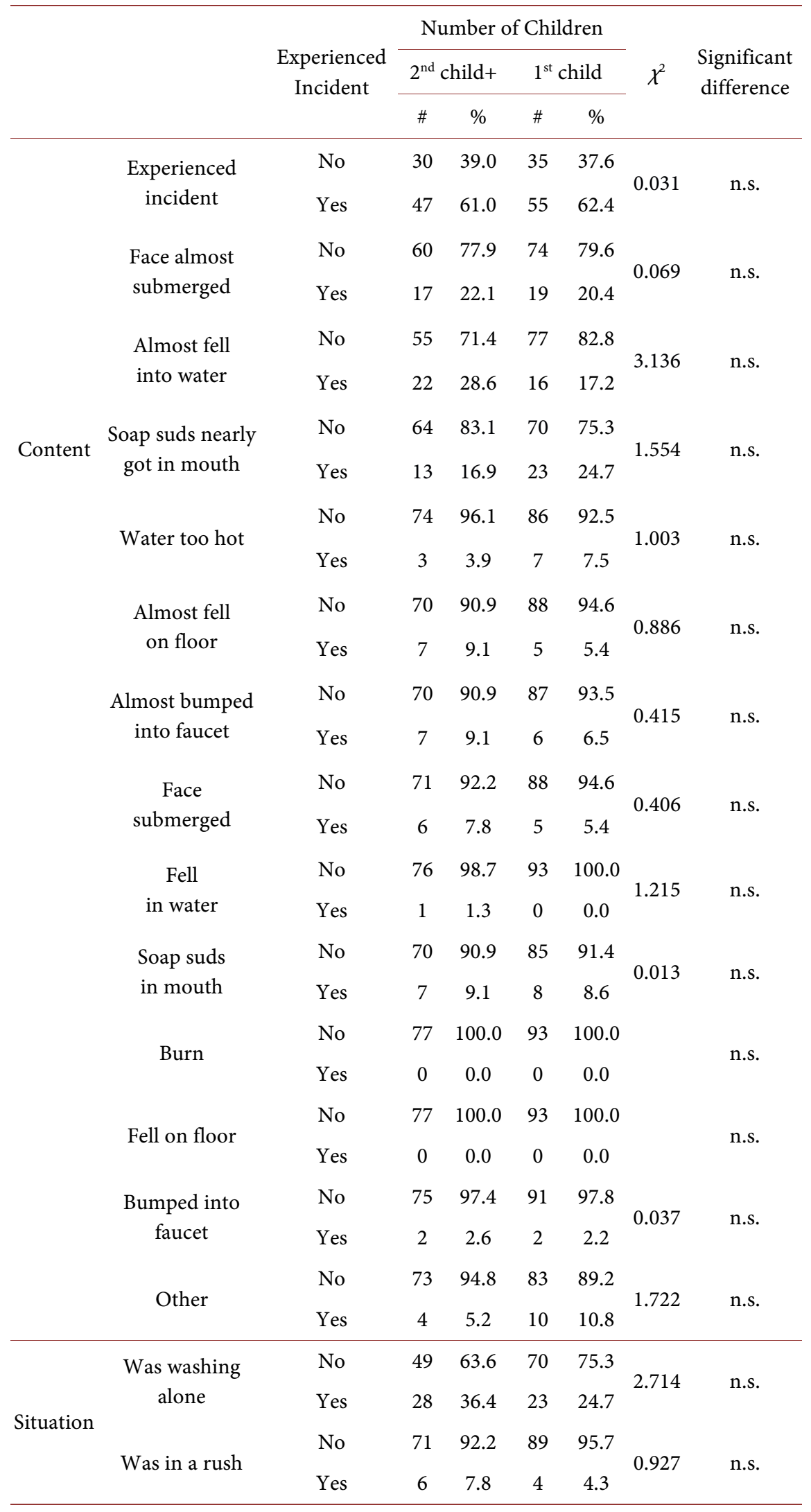




\section{Continued}

\begin{tabular}{|c|c|c|c|c|c|c|c|}
\hline \multirow{2}{*}{$\begin{array}{l}\text { Was taking care } \\
\text { of other children }\end{array}$} & No & 70 & 90.9 & 93 & 100.0 & \multirow{2}{*}{8.818} & \multirow{2}{*}{ ** } \\
\hline & Yes & 7 & 9.1 & 0 & 0.0 & & \\
\hline \multirow[b]{2}{*}{ Was distracted } & No & 76 & 98.7 & 93 & 100.0 & \multirow{2}{*}{1.215} & \multirow[b]{2}{*}{ n.s. } \\
\hline & Yes & 1 & 1.3 & 0 & 0.0 & & \\
\hline \multirow{2}{*}{$\begin{array}{l}\text { Wasn't } \\
\text { used to it }\end{array}$} & No & 71 & 92.2 & 61 & 65.6 & \multirow{2}{*}{17.193} & \multirow{2}{*}{ ** } \\
\hline & Yes & 6 & 7.8 & 32 & 34.4 & & \\
\hline \multirow{2}{*}{$\begin{array}{l}\text { Bath equipment } \\
\text { wasn't ready }\end{array}$} & No & 75 & 97.4 & 92 & 98.9 & \multirow{2}{*}{0.563} & \multirow{2}{*}{ n.s. } \\
\hline & Yes & 2 & 2.6 & 1 & 1.1 & & \\
\hline \multirow{2}{*}{$\begin{array}{l}\text { Child was in } \\
\text { poor mood }\end{array}$} & No & 74 & 96.1 & 91 & 97.8 & \multirow{2}{*}{0.450} & \multirow{2}{*}{ n.s. } \\
\hline & Yes & 3 & 3.9 & 2 & 2.2 & & \\
\hline \multirow{2}{*}{$\begin{array}{l}\text { Child moved } \\
\text { unexpectedly }\end{array}$} & No & 52 & 67.5 & 63 & 67.7 & \multirow{2}{*}{0.001} & \multirow{2}{*}{ n.s. } \\
\hline & Yes & 25 & 32.5 & 30 & 32.3 & & \\
\hline \multirow{2}{*}{ Other } & No & 74 & 96.1 & 85 & 91.4 & \multirow{2}{*}{1.542} & \multirow{2}{*}{ n.s. } \\
\hline & Yes & 3 & 3.9 & 8 & 8.6 & & \\
\hline
\end{tabular}

${ }^{* *}: \mathrm{p}<0.01$, n.s.: not significant.

Table 8. Comparison of incidents experienced during ablution and situations based on presence of instruction.

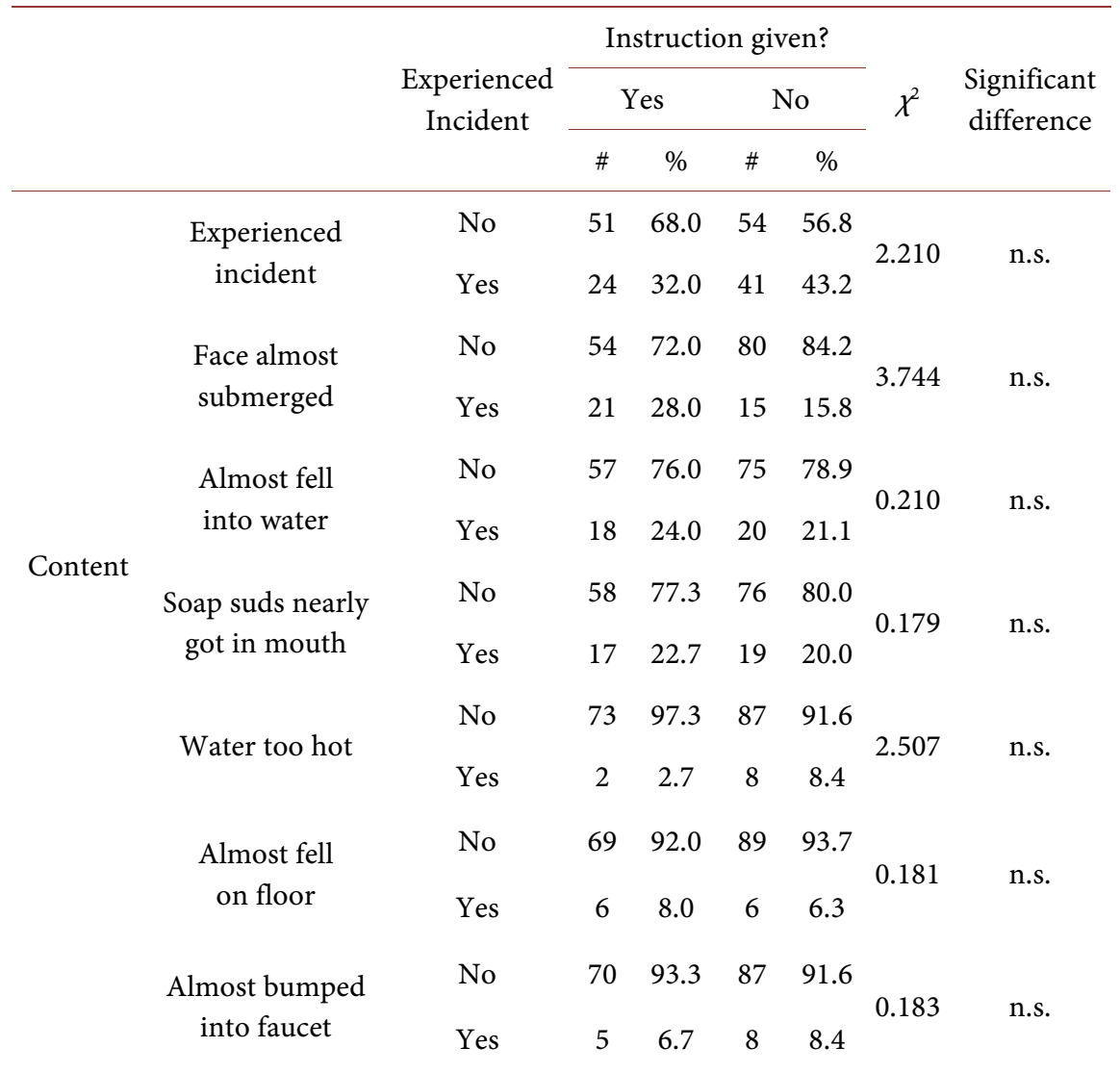




\section{Continued}

\begin{tabular}{|c|c|c|c|c|c|c|c|c|}
\hline & \multirow{2}{*}{ Face submerged } & No & 67 & 89.3 & 92 & 96.8 & \multirow{2}{*}{3.905} & \multirow{2}{*}{ n.s. } \\
\hline & & Yes & 8 & 10.7 & 3 & 3.2 & & \\
\hline & \multirow{2}{*}{ Fell in water } & No & 74 & 98.7 & 95 & 100.0 & \multirow{2}{*}{1.274} & \multirow{2}{*}{ n.s. } \\
\hline & & Yes & 1 & 1.3 & 0 & 0.0 & & \\
\hline & \multirow{2}{*}{$\begin{array}{l}\text { Soap suds } \\
\text { in mouth }\end{array}$} & No & 67 & 89.3 & 88 & 92.6 & \multirow{2}{*}{0.567} & \multirow{2}{*}{ n.s. } \\
\hline & & Yes & 8 & 10.7 & 7 & 7.4 & & \\
\hline & \multirow{2}{*}{ Burn } & No & 75 & 100.0 & 95 & 100.0 & & \multirow{2}{*}{ n.s. } \\
\hline & & Yes & 0 & 0.0 & 0 & 0.0 & & \\
\hline & \multirow{2}{*}{ Fell on floor } & No & 75 & 100.0 & 95 & 100.0 & & \multirow{2}{*}{ n.s. } \\
\hline & & Yes & 0 & 0.0 & 0 & 0.0 & & \\
\hline & \multirow{2}{*}{$\begin{array}{l}\text { Bumped } \\
\text { into faucet }\end{array}$} & No & 73 & 97.3 & 93 & 97.9 & \multirow{2}{*}{0.057} & \multirow{2}{*}{ n.s. } \\
\hline & & Yes & 2 & 2.7 & 2 & 2.1 & & \\
\hline & \multirow{2}{*}{ Other } & No & 48 & 64.0 & 71 & 74.7 & \multirow{2}{*}{0.010} & \multirow{2}{*}{ n.s. } \\
\hline & & Yes & 27 & 36.0 & 24 & 25.3 & & \\
\hline & \multirow{2}{*}{$\begin{array}{c}\text { Was } \\
\text { washing alone }\end{array}$} & No & 69 & 92.0 & 91 & 95.8 & \multirow{2}{*}{2.301} & \multirow{2}{*}{ n.s. } \\
\hline & & Yes & 6 & 8.0 & 4 & 4.2 & & \\
\hline & \multirow{2}{*}{ Was in a rush } & No & 71 & 94.7 & 92 & 96.8 & \multirow{2}{*}{1.087} & \multirow{2}{*}{ n.s. } \\
\hline & & Yes & 4 & 5.3 & 3 & 3.2 & & \\
\hline & \multirow{2}{*}{$\begin{array}{l}\text { Was taking care } \\
\text { of other children }\end{array}$} & No & 74 & 98.7 & 95 & 100.0 & \multirow{2}{*}{0.502} & \multirow{2}{*}{ n.s. } \\
\hline & & Yes & 1 & 1.3 & 0 & 0.0 & & \\
\hline & \multirow{2}{*}{ Was distracted } & No & 58 & 77.3 & 74 & 77.9 & & \\
\hline & & Yes & 17 & 22.7 & 21 & 22.1 & 1.274 & n.s. \\
\hline & & No & 74 & 98.7 & 93 & 97.9 & & \\
\hline Situation & Wasn't used to it & Yes & 1 & 1.3 & 2 & 2.1 & 0.008 & n.s. \\
\hline & Bath equipment & No & 48 & 64.0 & 67 & 70.5 & & \\
\hline & wasn't ready & Yes & 27 & 36.0 & 28 & 29.5 & 0.144 & 11.s. \\
\hline & Child was in & No & 70 & 93.3 & 89 & 93.7 & 1215 & \\
\hline & poor mood & Yes & 5 & 6.7 & 6 & 6.3 & & 10.0 \\
\hline & Child moved & No & 51 & 68.0 & 54 & 56.8 & 0816 & $\mathrm{n} s$ \\
\hline & unexpectedly & Yes & 24 & 32.0 & 41 & 43.2 & & ten \\
\hline & & No & 54 & 72.0 & 80 & 84.2 & & \\
\hline & Ginet & Yes & 21 & 28.0 & 15 & 15.8 & 0.009 & n.s. \\
\hline
\end{tabular}

n.s.: not significant. 
Table 9. Comparison of prevention measures taken to prevent ablution-related incidents between Primipara and Multipara.

\begin{tabular}{|c|c|c|c|c|c|c|c|}
\hline & \multirow{3}{*}{$\begin{array}{l}\text { Experienced } \\
\text { Incident }\end{array}$} & \multicolumn{4}{|c|}{ Number of Children } & \multirow{3}{*}{$x^{2}$} & \multirow{3}{*}{$\begin{array}{l}\text { Significant } \\
\text { difference }\end{array}$} \\
\hline & & \multicolumn{2}{|c|}{$2^{\text {nd }}$ child+ } & \multicolumn{2}{|c|}{$1^{\text {st }}$ child } & & \\
\hline & & $\#$ & $\%$ & $\#$ & $\%$ & & \\
\hline \multirow[b]{2}{*}{ No measures taken } & No & 54 & 70.1 & 80 & 86.0 & \multirow[b]{2}{*}{6.373} & \multirow[b]{2}{*}{ * } \\
\hline & Yes & 23 & 29.9 & 13 & 14.0 & & \\
\hline \multirow{2}{*}{$\begin{array}{l}\text { Give bath when } \\
\text { people are there to help }\end{array}$} & No & 41 & 53.2 & 28 & 30.1 & \multirow{2}{*}{9.353} & \multirow{2}{*}{ ** } \\
\hline & Yes & 36 & 46.8 & 65 & 69.9 & & \\
\hline \multirow{2}{*}{$\begin{array}{l}\text { Make use of bathing } \\
\text { equipment }\end{array}$} & No & 64 & 83.1 & 81 & 87.1 & \multirow{2}{*}{0.532} & \multirow{2}{*}{ n.s. } \\
\hline & Yes & 13 & 16.9 & 12 & 12.9 & & \\
\hline \multirow{2}{*}{$\begin{array}{l}\text { Request help from } \\
\text { childcare supporter }\end{array}$} & No & 76 & 98.7 & 92 & 98.9 & \multirow{2}{*}{0.018} & \multirow{2}{*}{ n.s. } \\
\hline & Yes & 1 & 1.3 & 1 & 1.1 & & \\
\hline \multirow{2}{*}{ Other } & No & 68 & 88.3 & 79 & 84.9 & \multirow{2}{*}{0.408} & \multirow{2}{*}{ n.s. } \\
\hline & Yes & 9 & 11.7 & 14 & 15.1 & & \\
\hline
\end{tabular}

${ }^{* *}: \mathrm{p}<0.01,{ }^{*}: \mathrm{p}<0.05$, n.s.: not significant.

Table 10. Comparison of prevention measures taken to prevent ablution-related incidents based on presence of instruction.

\begin{tabular}{|c|c|c|c|c|c|c|c|}
\hline & \multirow{3}{*}{$\begin{array}{l}\text { Experienced } \\
\text { Incident }\end{array}$} & \multicolumn{4}{|c|}{ Instruction given? } & \multirow{3}{*}{$\chi^{2}$} & \multirow{3}{*}{$\begin{array}{l}\text { Significant } \\
\text { difference }\end{array}$} \\
\hline & & \multicolumn{2}{|c|}{ Yes } & \multicolumn{2}{|c|}{ No } & & \\
\hline & & $\#$ & $\%$ & $\#$ & $\%$ & & \\
\hline \multirow[b]{2}{*}{ No measures taken } & No & 64 & 85.3 & 70 & 73.7 & \multirow[b]{2}{*}{3.407} & \multirow[b]{2}{*}{ n.s. } \\
\hline & Yes & 11 & 14.7 & 25 & 26.3 & & \\
\hline \multirow{2}{*}{$\begin{array}{l}\text { Give bath when people } \\
\text { are there to help }\end{array}$} & No & 28 & 37.3 & 41 & 43.2 & \multirow{2}{*}{0.590} & \multirow{2}{*}{ n.s. } \\
\hline & Yes & 47 & 62.7 & 54 & 56.8 & & \\
\hline \multirow{2}{*}{$\begin{array}{c}\text { Make use of bathing } \\
\text { equipment }\end{array}$} & No & 63 & 84.0 & 82 & 86.3 & \multirow{2}{*}{0.179} & \multirow{2}{*}{ n.s. } \\
\hline & Yes & 12 & 16.0 & 13 & 13.7 & & \\
\hline \multirow{2}{*}{$\begin{array}{l}\text { Request help from } \\
\text { childcare supporter }\end{array}$} & No & 74 & 98.7 & 94 & 98.9 & \multirow{2}{*}{0.028} & \multirow{2}{*}{ n.s. } \\
\hline & Yes & 1 & 1.3 & 1 & 1.1 & & \\
\hline \multirow[b]{2}{*}{ Other } & No & 63 & 84.0 & 84 & 88.4 & \multirow[b]{2}{*}{0.700} & \multirow{2}{*}{ n.s. } \\
\hline & Yes & 12 & 16.0 & 11 & 11.6 & & \\
\hline
\end{tabular}

n.s.: not significant.

a) Implementation (Table 11 and Table 12)

Table 11 shows the percentage of subjects who had transitioned from ablution to bathing in a normal bath. The conditions of bathing are shown in Table 12. 
Table 11. Transition from ablution to bathing $(n=170)$.

\begin{tabular}{ccc}
\hline & $\#$ & $\%$ \\
\hline Transitioned & 148 & 87.1 \\
Not transitioned & 22 & 12.9 \\
\hline
\end{tabular}

Table 12. State of children's bathing $(n=148)$.

\begin{tabular}{|c|c|c|c|}
\hline & & Number & $\%$ \\
\hline \multirow{4}{*}{ Primary bath giver } & Mother & 102 & 68.9 \\
\hline & Father & 47 & 31.8 \\
\hline & Maternal grandmother & 1 & 0.7 \\
\hline & No response & 1 & 0.7 \\
\hline \multirow{9}{*}{$\begin{array}{l}\text { Assists with bathing } \\
\text { (multiple response) }\end{array}$} & Mother & 48 & 32.4 \\
\hline & Father & 89 & 60.1 \\
\hline & Maternal grandmother & 27 & 18.2 \\
\hline & Maternal grandfather & 7 & 4.7 \\
\hline & Paternal grandmother & 2 & 1.4 \\
\hline & Sibling & 13 & 8.8 \\
\hline & None & 13 & 8.8 \\
\hline & Other & 3 & 2.0 \\
\hline & No response & 1 & 0.7 \\
\hline \multirow{5}{*}{$\begin{array}{c}\text { Cleansers used } \\
\text { (multiple response) }\end{array}$} & None & 1 & 0.7 \\
\hline & Solid soap & 23 & 15.5 \\
\hline & Liquid soap & 11 & 7.4 \\
\hline & Foam soap & 124 & 83.8 \\
\hline & No response & 2 & 1.4 \\
\hline \multirow{5}{*}{$\begin{array}{l}\text { Washing instruments } \\
\text { (multiple response) }\end{array}$} & Hands & 134 & 90.5 \\
\hline & Gauze & 94 & 63.5 \\
\hline & Towel & 4 & 2.7 \\
\hline & Other & 1 & 0.7 \\
\hline & No response & 2 & 1.4 \\
\hline \multirow{4}{*}{$\begin{array}{l}\text { Rinsing method } \\
\text { (multiple response) }\end{array}$} & Shower & 118 & 79.7 \\
\hline & Pouring water & 62 & 41.9 \\
\hline & Other & 3 & 2.0 \\
\hline & No response & 3 & 2.0 \\
\hline
\end{tabular}




\section{Continued}

\begin{tabular}{cccc}
\hline & None & 75 & 50.7 \\
& Bath seat & 38 & 25.7 \\
Bathing equipment & Bath mat & 29 & 19.6 \\
(multiple response) & Neck-worn flotation ring & 17 & 11.5 \\
& Other & 8 & 5.4 \\
& None & 1 & 0.7 \\
\hline
\end{tabular}

148 families (87.1\%) had transitioned from ablution to bathing. The main bath giver was the mother for 102 families (68.9\%) and the father for 47 families (31.8\%), while 89 fathers (60.1\%) and 48 mothers (32.4\%) filled an assistive role.

The most commonly used cleanser was foaming soap (124 families, $83.8 \%$ ). The most common washing implement used was the hands (134 families, $90.5 \%$ ), followed by gauze (94 families, 63.5\%). 118 families (79.7\%) rinsed with the showerhead and $62(41.9 \%)$ by pouring water over the infant. 75 families (50.7\%) did not use any bathing equipment. The most commonly used pieces of equipment were bath seats (38 families, $25.7 \%$ ), bath mats (29 families, $19.6 \%$ ), and neck-worn flotation rings (17 families, 11.5\%).

b) The state of bathtime dangers (Table 13, Figures 4-6)

Table 13 shows whether subjects experienced bathtime incidents or not. Figure 4 and Figure 5 show what dangers were experienced and the situations in which the incidents occurred in. Figure 6 shows the measures taken to prevent incidents.

96 subjects (64.9\%) responded that they had experienced incidents. Among the subjects who had experienced incidents, the most common were, in order of frequency, getting soap in the mouth $(\mathrm{n}=35,36.5 \%)$, near submersion of the face $(n=33,34.4 \%)$, and near drops onto the floor $(n=20,20.8 \%)$. The most common situations in which incidents occurred were the child moving unexpectedly $(n=57,59.4 \%)$, while giving a bath by oneself $(n=45,46.9 \%)$, and being unfamiliar with the process $(\mathrm{n}=17,17.7 \%)$.

The most common responses concerning measures taken to prevent incidents were bathing the infant when people were around to help $(n=63,42.6 \%)$, taking no measures $(\mathrm{n}=49,33.1 \%)$, and using bathing equipment such as bath seats ( $\mathrm{n}$ $=30,20.3 \%)$.

c) The state of instruction (Table 14)

Table 14 shows the state of instruction pertaining to the dangers that can occur during bathtime and the prevention of such dangers.

139 subjects $(81.8 \%)$ had not received instruction regarding the possible dangers that can occur during bathtime or the prevention of such dangers. Among 31 subjects who did receive instruction, the content of that instruction was the types of incidents that can occur $(\mathrm{n}=30,96.8 \%)$ and prevention methods $(\mathrm{n}=$ $10,32.3 \%)$. The most common settings in which instruction was received were 
Table 13. Experienced incidents during bathing $(\mathrm{n}=148)$.

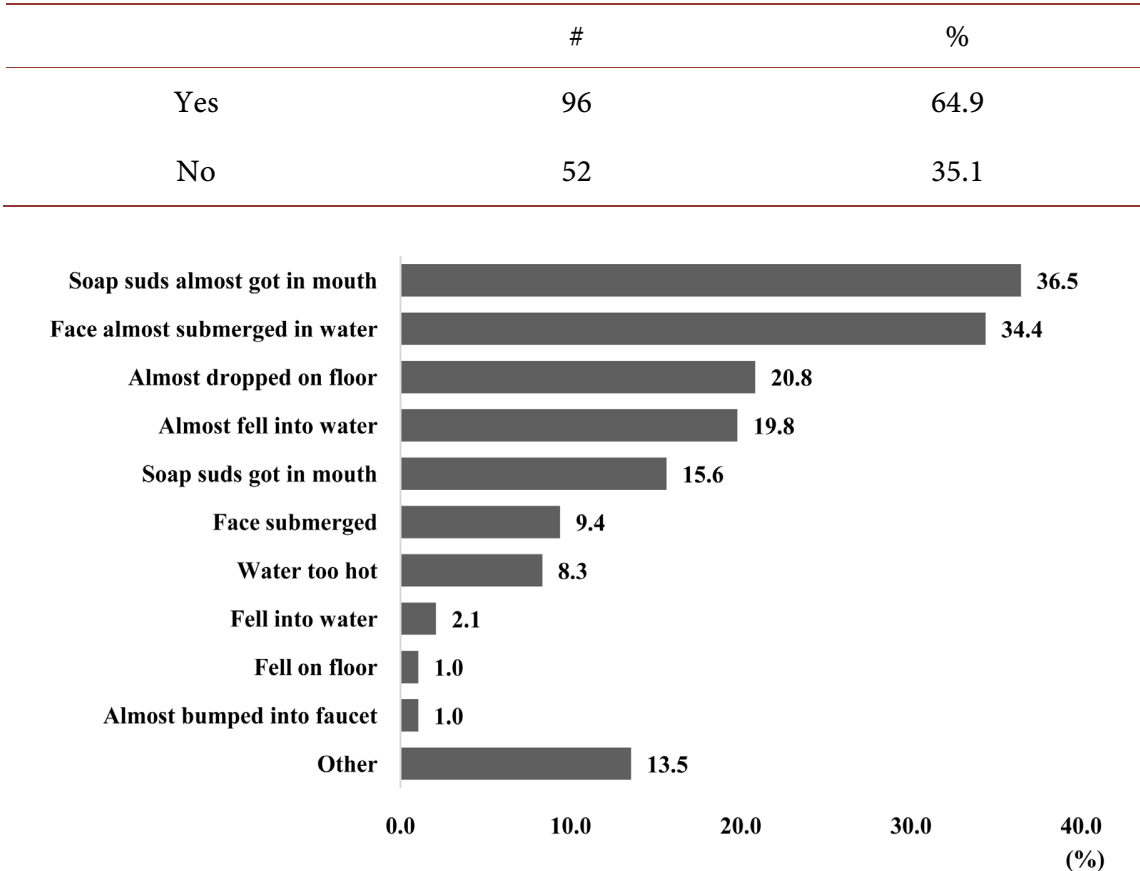

Figure 4. Incidents experienced during bathing $(\mathrm{n}=96)$ (multiple response).

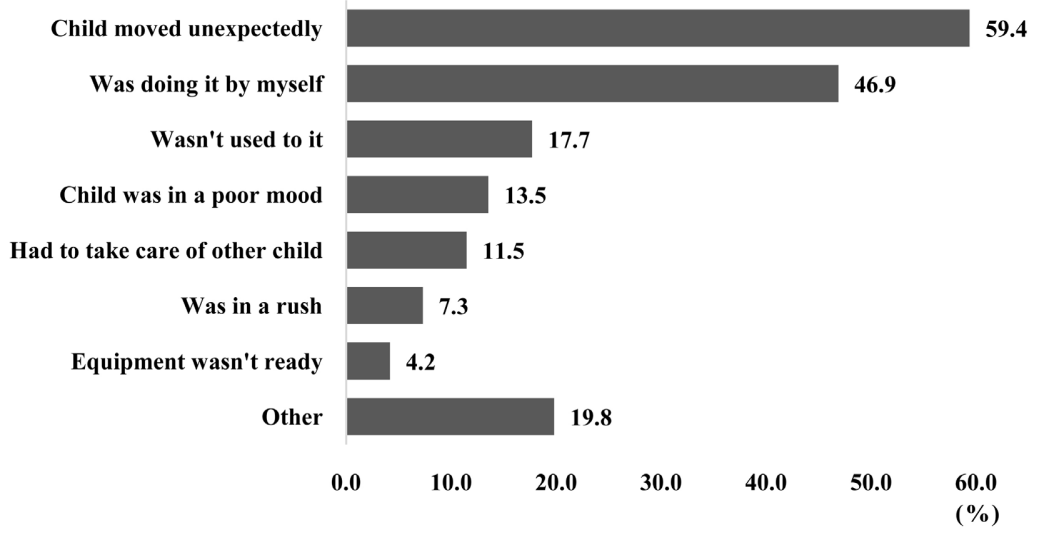

Figure 5. Situations when incidents occurred during bathing $(\mathrm{n}=96)$ (Multiple response).

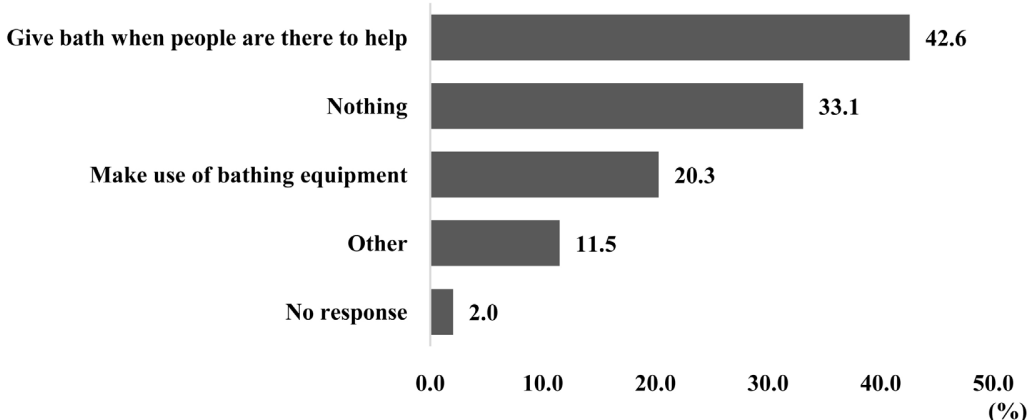

Figure 6. Measures taken to prevent incidents during bathing $(\mathrm{n}=148)$ (Multiple response). 
Table 14. State of instruction concerning possible bathing incidents.

\begin{tabular}{|c|c|c|c|}
\hline & & $\#$ & $\%$ \\
\hline \multirow{3}{*}{$\begin{array}{c}\text { Content } \\
(\mathrm{n}=31) \\
\text { (multiple response) }\end{array}$} & What kinds of incidents can happen & 30 & 96.8 \\
\hline & Prevention methods & 10 & 32.3 \\
\hline & Other & 1 & 3.2 \\
\hline \multirow{6}{*}{$\begin{array}{l}\text { Place of instruction } \\
\qquad(\mathrm{n}=31) \\
\text { (multiple response) }\end{array}$} & Maternity classes & 7 & 22.6 \\
\hline & Parenting classes & 2 & 6.5 \\
\hline & During hospital stay after childbirth & 21 & 67.7 \\
\hline & Health exam & 3 & 9.7 \\
\hline & Home visit & 2 & 6.5 \\
\hline & Other & 3 & 9.7 \\
\hline \multirow{6}{*}{$\begin{array}{l}\text { Source of information } \\
\qquad(\mathrm{n}=170) \\
\text { (multiple response) }\end{array}$} & Internet & 59 & 34.7 \\
\hline & Maternity magazine/parenting materials & 39 & 22.9 \\
\hline & Nurse, midwife, or public health nurse & 50 & 29.4 \\
\hline & No information received & 41 & 24.1 \\
\hline & Other & 11 & 6.5 \\
\hline & No response & 7 & 4.1 \\
\hline
\end{tabular}

during the hospital stay after childbirth $(\mathrm{n}=21,67.7 \%)$ and in maternity classes $(\mathrm{n}=7,22.6 \%)$.

The most common sources of information concerning bathtime dangers were the Internet $(n=59,34.7 \%)$ and from a nurse/midwife/public health nurse.

d) Comparison of experienced dangers based on number of children and presence of instruction (Table 15 and Table 16)

Table 15 compares subjects by the number of children they have while Table 16 compares subjects based on whether they received instruction or not.

When comparing by the number of children, more subjects with a single child selected "soap got in mouth" than those with multiple children. As for situations, more subjects with a single child selected "wasn't used to it" than those with multiple children, while significantly more subjects with multiple children selected "taking care of other children" than those with a single child. No significant differences were seen between subjects who received instruction and those who did not.

e) Comparison of prevention measures based on number of children and presence of instruction (Table 17 and Table 18)

Table 17 and Table 18 show the measures taken to prevent accidents. Table 17 compares subjects by the number of children they have while Table 18 compares subjects based on whether they received instruction or not.

No significant differences were seen between subjects when comparing them by number of children or whether they had received instruction. 
Table 15. Comparison of incidents experienced during bathing and situations between Primipara and Multipara.

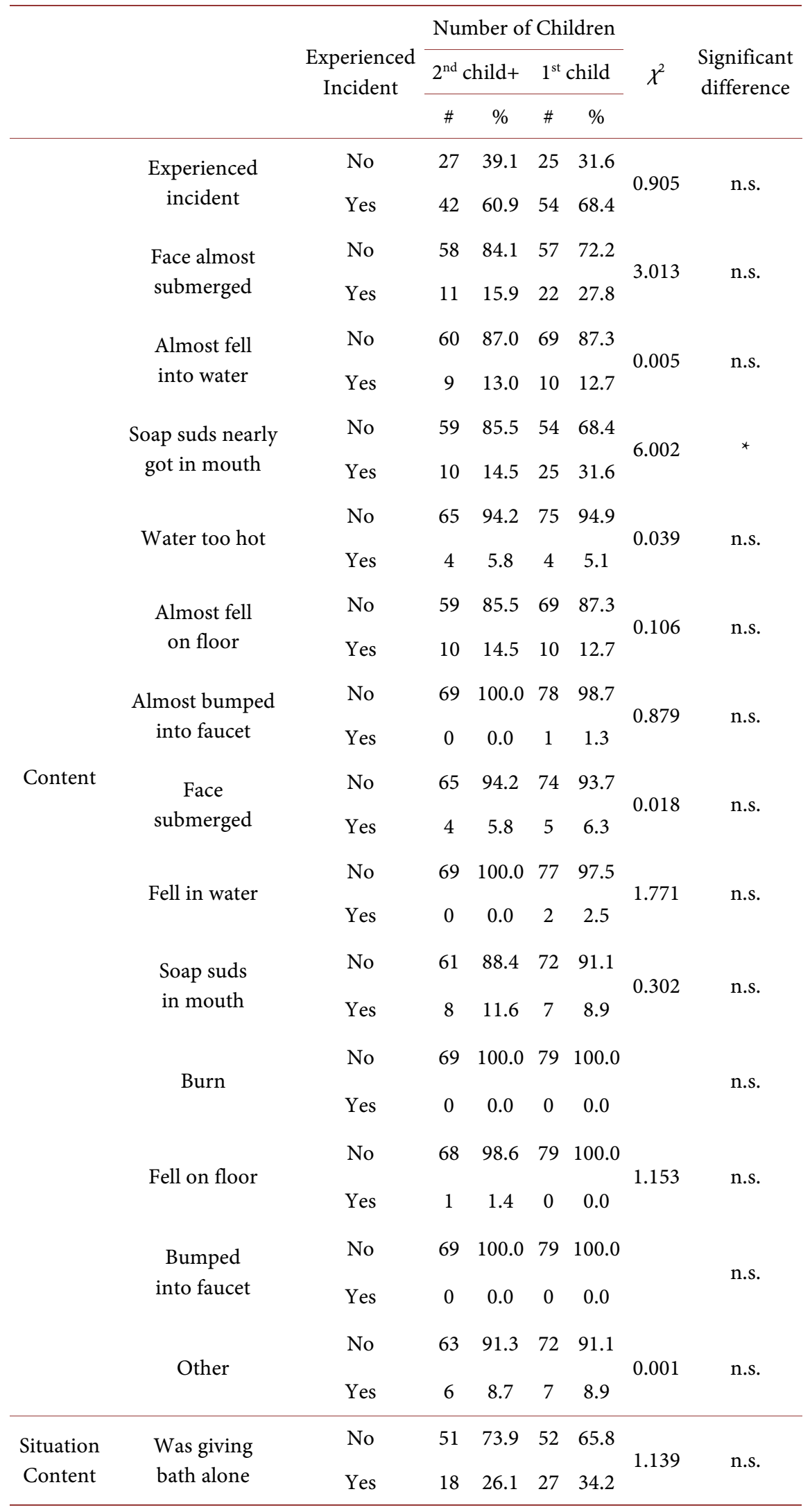




\section{Continued}

\begin{tabular}{|c|c|c|c|c|c|c|c|}
\hline \multirow[b]{2}{*}{ Was in a rush } & No & 66 & 95.7 & 75 & 94.9 & \multirow{2}{*}{0.042} & \multirow[b]{2}{*}{ n.s. } \\
\hline & Yes & 3 & 4.3 & 4 & 5.1 & & \\
\hline \multirow{2}{*}{$\begin{array}{l}\text { Was taking care } \\
\text { of other children }\end{array}$} & No & 58 & 84.1 & 79 & 100.0 & \multirow{2}{*}{13.605} & \multirow{2}{*}{$* *$} \\
\hline & Yes & 11 & 15.9 & 0 & 0.0 & & \\
\hline \multirow{2}{*}{ Was distracted } & No & 69 & 100.0 & 79 & 100.0 & & \multirow{2}{*}{ n.s. } \\
\hline & Yes & 0 & 0.0 & 0 & 0.0 & & \\
\hline \multirow{2}{*}{ Wasn't used to it } & No & 67 & 97.1 & 64 & 81.0 & \multirow{2}{*}{9.377} & \multirow{2}{*}{$* *$} \\
\hline & Yes & 2 & 2.9 & 15 & 19.0 & & \\
\hline \multirow{2}{*}{ Wasn't prepared } & No & 68 & 98.6 & 76 & 96.2 & \multirow{2}{*}{0.772} & \multirow{2}{*}{ n.s. } \\
\hline & Yes & 1 & 1.4 & 3 & 3.8 & & \\
\hline \multirow{2}{*}{$\begin{array}{l}\text { Child was } \\
\text { in poor mood }\end{array}$} & No & 66 & 95.7 & 69 & 87.3 & \multirow{2}{*}{3.175} & \multirow{2}{*}{ n.s. } \\
\hline & Yes & 3 & 4.3 & 10 & 12.7 & & \\
\hline \multirow{2}{*}{$\begin{array}{l}\text { Child moved } \\
\text { unexpectedly }\end{array}$} & No & 46 & 66.7 & 45 & 57.0 & \multirow{2}{*}{1.465} & \multirow{2}{*}{ n.s. } \\
\hline & Yes & 23 & 33.3 & 34 & 43.0 & & \\
\hline \multirow{2}{*}{$\begin{array}{c}\text { Experienced } \\
\text { dangerous incident }\end{array}$} & No & 60 & 87.0 & 69 & 87.3 & \multirow{2}{*}{0.005} & \multirow{2}{*}{ n.s. } \\
\hline & Yes & 9 & 13.0 & 10 & 12.7 & & \\
\hline
\end{tabular}

${ }^{* *}: \mathrm{p}<0.01,{ }^{*}: \mathrm{p}<0.05$, n.s.: not significant.

Table 16. Comparison of incidents experienced during bathing and situations based on presence of instruction.

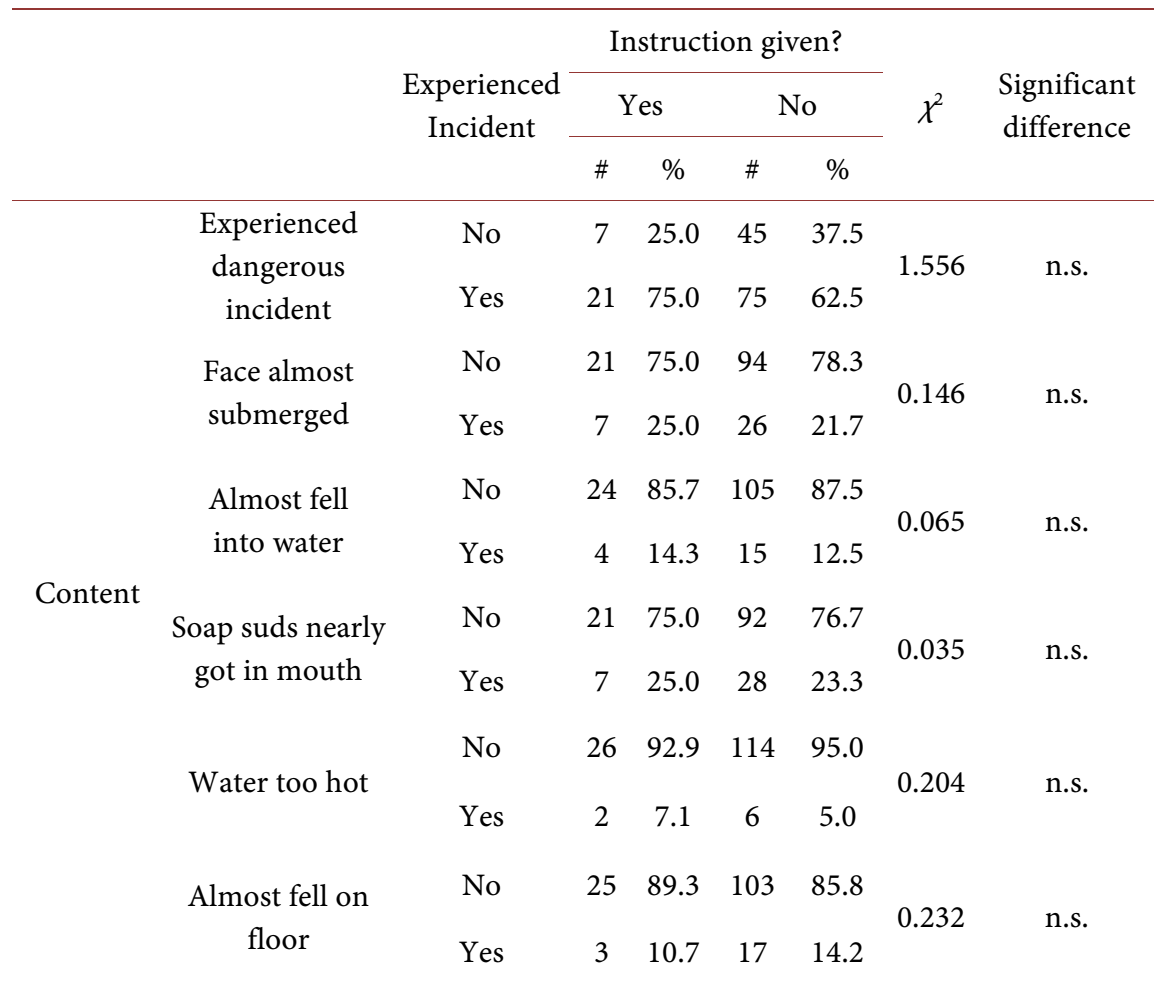




\section{Continued}

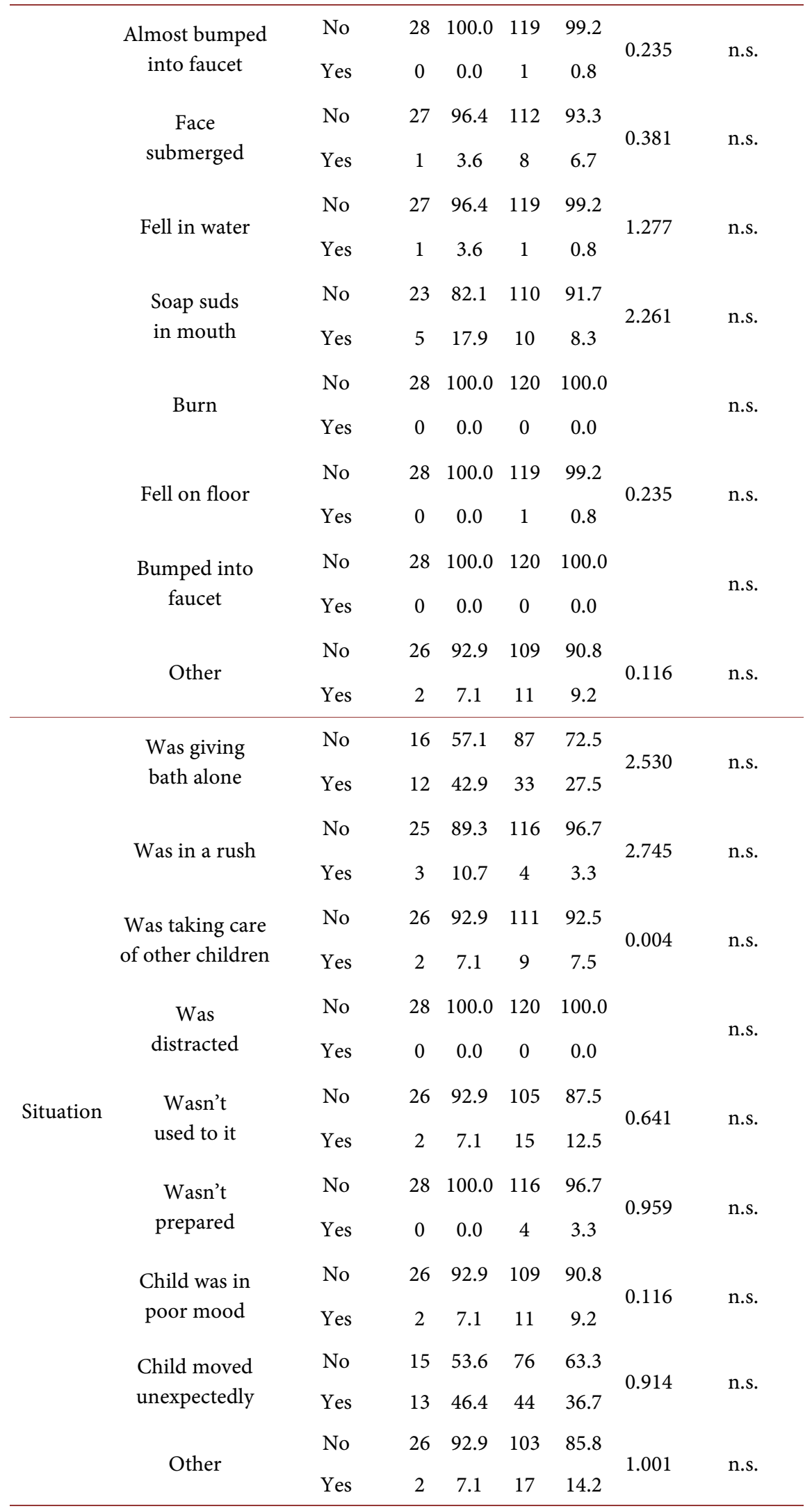

n.s.: not significant. 
Table 17. Comparison of prevention measures taken to prevent bathing-related incidents between Primipara and Multipara.

\begin{tabular}{|c|c|c|c|c|c|c|c|}
\hline & \multirow{3}{*}{$\begin{array}{l}\text { Experienced } \\
\text { Incident }\end{array}$} & \multicolumn{4}{|c|}{ Number of Children } & \multirow{3}{*}{$x^{2}$} & \multirow{3}{*}{$\begin{array}{l}\text { Significant } \\
\text { difference }\end{array}$} \\
\hline & & \multicolumn{2}{|c|}{$2^{\text {nd }}$ child +} & \multicolumn{2}{|c|}{$1^{\text {st }}$ child } & & \\
\hline & & $\#$ & $\%$ & $\#$ & $\%$ & & \\
\hline \multirow{2}{*}{$\begin{array}{l}\text { No measures } \\
\text { taken }\end{array}$} & No & 48 & 69.6 & 51 & 64.6 & \multirow{2}{*}{0.417} & \multirow{2}{*}{ n.s. } \\
\hline & Yes & 21 & 30.4 & 28 & 35.4 & & \\
\hline \multirow{2}{*}{$\begin{array}{l}\text { Give bath when } \\
\text { people are there to help }\end{array}$} & No & 39 & 56.5 & 46 & 58.2 & \multirow{2}{*}{0.044} & \multirow{2}{*}{ n.s. } \\
\hline & Yes & 30 & 43.5 & 33 & 41.8 & & \\
\hline \multirow{2}{*}{$\begin{array}{c}\text { Make use of } \\
\text { bathing equipment }\end{array}$} & No & 54 & 78.3 & 64 & 81.0 & \multirow{2}{*}{0.173} & \multirow{2}{*}{ n.s. } \\
\hline & Yes & 15 & 21.7 & 15 & 19.0 & & \\
\hline \multirow{2}{*}{$\begin{array}{l}\text { Request help from } \\
\text { childcare supporter }\end{array}$} & No & 69 & 100.0 & 79 & 100.0 & & \multirow{2}{*}{ n.s. } \\
\hline & Yes & 0 & 0.0 & 0 & 0.0 & & \\
\hline \multirow{2}{*}{ Other } & No & 64 & 92.8 & 67 & 84.8 & \multirow{2}{*}{2.286} & \multirow{2}{*}{ n.s. } \\
\hline & Yes & 5 & 7.2 & 12 & 15.2 & & \\
\hline
\end{tabular}

n.s.: not significant.

Table 18. Comparison of prevention measures taken to prevent ablution-related incidents based on presence of instruction.

\begin{tabular}{|c|c|c|c|c|c|c|c|}
\hline & \multirow{3}{*}{$\begin{array}{c}\text { Experienced } \\
\text { Incident }\end{array}$} & \multicolumn{4}{|c|}{ Instruction given? } & \multirow{3}{*}{$x^{2}$} & \multirow{3}{*}{$\begin{array}{l}\text { Significan } \\
\text { difference }\end{array}$} \\
\hline & & \multicolumn{2}{|c|}{ Yes } & \multicolumn{2}{|c|}{ No } & & \\
\hline & & $\#$ & $\%$ & $\#$ & $\%$ & & \\
\hline \multirow{2}{*}{$\begin{array}{l}\text { No measures } \\
\text { taken }\end{array}$} & No & 20 & 71.4 & 79 & 65.8 & \multirow{2}{*}{0.321} & \multirow{2}{*}{ n.s. } \\
\hline & Yes & 8 & 28.6 & 41 & 34.2 & & \\
\hline \multirow{2}{*}{$\begin{array}{l}\text { Wash when people } \\
\text { are there to help }\end{array}$} & No & 14 & 50.0 & 71 & 59.2 & \multirow{2}{*}{0.780} & \multirow{2}{*}{ n.s. } \\
\hline & Yes & 14 & 50.0 & 49 & 40.8 & & \\
\hline \multirow{2}{*}{$\begin{array}{c}\text { Make use of } \\
\text { bathing equipment }\end{array}$} & No & 22 & 78.6 & 96 & 80.0 & \multirow{2}{*}{0.029} & \multirow{2}{*}{ n.s. } \\
\hline & Yes & 6 & 21.4 & 24 & 20.0 & & \\
\hline \multirow{2}{*}{$\begin{array}{l}\text { Request help from } \\
\text { childcare supporter }\end{array}$} & No & 28 & 100.0 & 120 & 100.0 & & \multirow{2}{*}{ n.s. } \\
\hline & Yes & 0 & 0.0 & 0 & 0.0 & & \\
\hline \multirow{2}{*}{ Other } & No & 25 & 89.3 & 106 & 88.3 & \multirow{2}{*}{0.020} & \multirow{2}{*}{ n.s. } \\
\hline & Yes & 3 & 10.7 & 14 & 11.7 & & \\
\hline
\end{tabular}

n.s.: not significant.

6) Opinions and requests for nurses concerning bathing

72 subjects $(42.4 \%)$ submitted freeform responses containing their opinions and requests for nursing professionals concerning bathing.

Categories of opinions and requests for nursing professionals are listed below, with specific examples of each in parentheses: bathing technique ("They told me 
how to wash my baby, but I'm on my own now that we started giving [him] regular baths. I'm not sure how long I should be bathing [him] for."), concrete examples of dangers ("They didn't warn me what to be careful about when giving my baby a bath, like slipping or [water and soap] getting in the baby's eyes and ears. I wish they had told me more."), methods of preventing accidents (safe and efficient bathing procedures), methods and caution points for bathing multiple children at once (what to do when my older child is there too), methods and caution points for giving a bath by oneself (how to bathe my baby when I'm watching it by myself), methods and caution points for bathing together with one's baby (where and how the mother can safely hold the baby while she washes herself), using bath equipment (positive and negative points of bath seats, bath mats, bath sponges, etc.), the timing/frequency of instruction (" $I$ wasn't sure when to ask about bathing. They should make it easier to find out."), and how to deal with accidents when they occur (what to do when soap gets in the baby's eyes or mouth).

Families with multiple children expressed opinions in the categories of methods and caution points for bathing multiple children at once, methods and caution points for giving a bath by oneself, using bathing equipment, and concrete examples of dangers.

Families with a single child expressed opinions in the categories of bathing technique, methods and caution points for giving a bath by oneself, and concrete examples of dangers.

\section{Observations}

1) Subject characteristics and background

According to the 2019 Comprehensive Survey of Living Conditions, [16] the breakdown of employment status of mothers whose youngest child was one year of age in 2019 was $33.6 \%$ full-time employees, $19.3 \%$ part-time/temporary workers, $41.6 \%$ unemployed. The results of this study line up with the national survey, with $60 \%$ of mothers being employed (including those on maternity leave).

About half of mothers and fathers answered that they bathe in the tub every day. Since bathing in a tub is an essential everyday custom in Japan, it is also common to use a tub of hot water when washing or bathing infants as well, which may present many opportunities for incidents to occur.

2) The state of ablution and bathing

In Japan, the amount of time women spend on childcare and housework is longer than in Western countries. These long hours create a burden for women. In this study, $75.3 \%$ of mothers and $20.3 \%$ of fathers identified as being in charge of washing their baby, while $68.9 \%$ of mothers and $31.8 \%$ of fathers identified as being in charge of bathing. Unlike breastfeeding and other child raising activities that only mothers take part in, ablution and bathing are activities in which fathers and other family members can participate in. However, $92.4 \%$ of fathers are employed, and in many households may be unable to help with bathing. With 
the current state of working conditions in Japan it may be unreasonable to expect fathers to participate in childrearing as a measure to enable safe infant bathing. It is necessary to realize a society in which fathers are able to participate in childcare as well as to consider and spread techniques for safely bathing one's infant when by oneself.

The most common cleanser used for ablution and bathing was foaming soap. Proper lathering is an important part of the action of soap. Self-foaming soap can used without taking your eyes off the infant and is effective at reducing some of the danger associated with ablution and bathing. However, as could be seen in subjects' responses, soap can get in the baby's mouth, and can lead to slips and drops. It is important to spread the knowledge of dangers associated with the use of foaming soap.

$50.7 \%$ of respondents reported to not use any bathing equipment, which was the largest group. Subjects used bath seats (25.7\%), bath mats (19.6\%), and neckworn flotation rings $(11.5 \%)$. There are a wide variety of washing and bathing products on the market. Proper use of these products may make bathing safer and easier, which could be effective at reducing the risk associated with infant ablution and bathing. In this study, $20.3 \%$ of subjects reported that they use bathing equipment as a way to prevent bathtime dangers. However, improper use of these products may potentially cause incidents. In particular, there have been reports of drownings during the use of neck-worn flotation rings. There are still mothers and families using these products. This was indicated our data: " $I$ didn't do this some people use neck floaties for baby swimming in the bathtub without knowing how dangerous those products can be (mostly on social media). It would be good to spread the word that those neck floaties are dangerous." One cause of incidents with infants is the improper use of baby care products [17]. It is important to consider how we might prevent avoidable risks and protect mothers, families, and their babies from these dangerous experiences.

3) The state of experienced dangers

$60.0 \%$ of subjects experienced incidents during ablution. The dangers most commonly experienced by these families were the baby nearly falling into the water (36.2\%), the baby's face nearly being submerged (34.3\%), and the baby nearly getting soap in its mouth (34.3\%). Furthermore, $64.9 \%$ of subjects experienced incidents during bathing. The dangers most commonly experienced by these families were soap nearly getting in the baby's mouth (36.5\%), the baby's face nearly being submerged (34.4\%), and the baby nearly falling to the floor (20.8\%).

It is common for babies to put their soapy hands in their mouths while they are being bathed. Through awareness of measures such as quick rinsing of any soap that gets on the hands, using a small amount of soap to minimize the effect it will have on the infant's health, and removing any soap that does get in the mouth, mothers and families can prevent incidents, as well as reduce unnecessary stress. Drowning and falls however are major risks to the life and health of the infant. Bathtime drownings involving infants younger than one year of age 
are 143 times more common than among children ages 5 - 19 [18], and it has been reported that 5 in 8 drownings involved infants younger than one year of age [19]. In light of this, preventative measures are of utmost importance.

$55.9 \%$ of subjects had not received instruction on the potential dangers which can occur during ablution, and $81.8 \%$ of subjects had not received instruction on the potential dangers that can occur during bathing. The sources of information on ablution reported were nurse/midwife/public health nurse $(67.1 \%)$ and maternity magazine/childcare books (25.9\%), while the sources reported for information on bathing were the Internet (34.7\%) and nurse/midwife/public health nurse (29.4\%).

Instruction on ablution mainly takes place during the post-delivery hospital stay. Instruction on ablution is also sometimes given as a part of health education before delivery. In our previous survey, $90 \%$ of mothers of infants aged $3-4$ months had received instruction on ablution [3]. The content of this instruction was how to wash, how to hold the infant, required equipment, and how to rinse for over $80 \%$. However, in this study fewer than half of subjects reported that they received instruction on ablution. The instruction on ablution currently in use in Japan focuses on ablution technique but does not adequately cover risk prevention.

Fewer than $80 \%$ of subjects in the previous survey had received instruction regarding bathing their infants in a normal-sized bathtub [3]. Those results suggested that mothers and families were obtaining information themselves through a variety of media. Bathing uses much more water than ablution, and it is common for family members to wash their own bodies while bathing their infant, which makes it difficult to keep a constant watch on the child. Furthermore, infants move more actively as they develop, which carries a major risk of injury during a bath. It is important to provide information to prevent such injuries.

It has been reported that $81.1 \%$ of mothers use the Internet to obtain childcare information [20]. Similarly, the Internet was most commonly used source for information on bathtime dangers in this study as well. The Internet is a widely used source for information on ablution and bathing for mothers and families. Querying Google, one of the leading Internet search engines, for videos on ablution produced over 1,600,000 videos. However, these videos are more often only footage of a parent washing their baby, or about the general steps of washing/bathing one's infant or preventing skin issues. Searching for videos on bathing in the same way resulted in approximately 420,000 hits, but the majority of these were introducing bath products, with the rest being videos parents took of their babies in the bath. From this situation, it is clear that the Internet is not an effective source of information on bathtime risk prevention in present-day Japan.

One major cause of accidents is the lack of awareness and knowledge mothers and families have. Instruction is needed to help counter this. The most common situations in which incidents were experienced while washing one's infant were 
the child moving unexpectedly (52.4\%), bathing the infant by oneself $(48.6 \%)$, and being unfamiliar with the process (36.2\%). Similarly, the most common situations in which incidents were experienced during everyday bathing were also the child moving unexpectedly (59.4\%), bathing the infant by oneself (46.9\%), and being unfamiliar with the process (17.7\%). For infants ages 3 - 4 months in particular, the change in environment from the hospital to washing at home, the lack of education about infant development, the lack of experience with the process, and fatigue from the combination of childcare and household upkeep create a situation in which incidents are more likely to occur. By providing mothers and family members with information on possible dangers and how they can be prevented, we may be able to stop such incidents before they occur.

When we compared the incidents experienced between families with a single child and those with multiple children, for both ablution- and bathing-related incidents, more subjects with a single child chose "not used to it" as the situation in which they experienced an incident than those with multiple children, and significantly more subjects with multiple children chose "taking care of other children" than those with a single child. Additionally, when it came to bathingrelated incidents, more families with a single child chose "soap nearly got in mouth" as a danger they had experienced than those with multiple children. Familiarity plays a major role in the safety of day-to-day childcare skills, and unfamiliarity with these skills may lead to increased risk, particularly for families dealing with their first child. It is important that mothers and families recognize the connection between inexperience and risk, as well as the role that instruction plays in making up for a lack of experience. Regarding the common incident of soap getting in mouth being more common among single-child families than multi-child families, a lack of knowledge about the movements of infants may be to blame.

Losing sight of one's baby plays a major role in potential accidents. Families with multiple children must often see to the needs of multiple children at once, and while doing so their attention is divided. This is likely the reason that subjects with multiple children so often experienced incidents in that situation. According to existing studies, $67 \%$ of drowning incidents occurred when no family member was present [18], and $15.4 \%$ of drownings of infants younger than 1 year of age happened during bathing [17].

No significant differences were found between subjects who had received instruction on either ablution or bathing and those who had not. The current instruction mothers and families receive may not be effective enough at preventing risk. Supplementing current instruction with what the dangers are, how to prevent them, and the measures families are already taking may lead to improved risk prevention. Furthermore, one common opinion/request for nursing staff seen for both ablution and bathing was how to deal with accidents. The mother is most often the one to discover the body after a drowning incident, However, it has been reported that fewer than half of the members of a given family will know first aid procedures for drowning [21], and resuscitation by the discoverer 
cannot be relied upon [8]. Reacting appropriately in response to an emergency is of great importance in saving the infant's life. For this reason, the proper emergency measures must be made common knowledge.

\section{Study Limitations and Future Matters}

This study was limited by the narrow scope of the target locale. In the future, a wider area should be studied, comparison should be done with other countries, and the risks of ablution and bathing exposed by this study should be widely communicated. We plan to create educational materials covering risk prevention for mothers and families based on these results and to develop an intervention study.

\section{Conclusions}

Measures must be taken to assist mothers and their families in safely and confidently bathing their newborns. This study was conducted with the purpose of exploring the conditions in Japan regarding the dangers related to ablution and bathing experienced by 170 families with infants aged 3 - 4 months. The following points have been made clear through this study:

1) $60.0 \%$ of subjects experienced incidents during ablution. In order of frequency, the incidents most commonly experienced were the baby nearly falling into the water the baby's face nearly being submerged, and the baby nearly getting soap in its mouth.

2) $64.9 \%$ of subjects experienced incidents during bathing. In order of frequency, the incidents most commonly experienced were soap nearly getting in the baby's mouth, the baby's face nearly being submerged, and the baby nearly falling to the floor.

3) $55.9 \%$ of subjects had not received instruction on the potential dangers which can occur during ablution, and $81.8 \%$ of subjects had not received instruction on the potential dangers that can occur during bathing.

4) When comparing the incidents experienced between families with a single child and those with multiple children, for both ablution- and bathing-related incidents, more subjects with a single child chose "not used to it" as the situation in which they experienced an incident than those with multiple children, and significantly more subjects with multiple children chose "taking care of other children" than those with a single child.

\section{Acknowledgements}

We would like to extend our sincere gratitude to the mothers and families who so graciously offered their valuable time to assist in our study, the many helpful staff of the health center, and all who lent us their guidance along the way.

This study was conducted with the assistance of the JSPS Scientific Research Grant (JP20K 19151).

This study is intended to be part of a dissertation for the Doctoral Program at the Osaka Medical and Pharmaceutical University Graduate School of Nursing. 


\section{Conflicts of Interest}

There are no conflicts of interest related to this study.

\section{References}

[1] Ministry of Health, Labour, and Welfare of Japan (2020) Summary of 2019 Survey of Medical Institutions and Hospital Report. 21-23.

https://www.mhlw.go.jp/toukei/saikin/hw/iryosd/19/dl/03byouin01.pdf

[2] Higuchi, S., Notsu, A., Umeno, Y., et al. (2017) Current Trends and Issues in Early Neonatal Hygiene and Skin Care in Japan. Maternal Health, 58, 91-99.

[3] Chikazawa, S. and Sasaki, A. (2020) Study on Troubles of Primiparas and Multiparas in Bathing Neonates and Infants. Journal of the Japan Maternal and Infant Care Association, 13, 25-36.

[4] Akiyama, R., Hiramoto, R., Komori, I., et al. (2010) An 11-Year-and-Six-Month Retrospective of 21 Cases of Drowning in Children at this Institution. Japanese Journal of Pediatrics, 63, 1189-1195.

[5] Ikemoto, W., Kuroiwa, Y., Honma, J., et al. (2002) An 8-Year Retrospective of Child Drowning Victims at This Institution. Medical Journal of Asahikawa Red Cross Hospital, 15, 28-31.

[6] Imataka, J., Kurosawa, H., Sugiyama, S., et al. (2001) The State and Prognosis of Drowning Incidents in Children: Through a Clinical Study of 33 Child Drownings. Japanese Journal of Pediatrics, 54, 103-110.

[7] Kato, Y., Takamine, C., Nakatsuji, H., et al. (2013) Accidents Occur in Spite of Infant Bathing Equipment: A Tally of Postcard Accident Surveys Targeting Infants Ages 0-12 Months. Pediatric Health Research, 72, 267-273.

[8] Matsue, Y., Nakamura, T., Sato, H., et al. (2007)The Importance of Basic Life Support in Drowning Incidents: An Examination of 37 Child Drownings. Japanese Journal of Pediatrics, 60, 1195-1199.

[9] Chikazawa, S. (2017) Literature Review Regarding Bathing of Newborns and Infants. Osaka Medical College Journal of Nursing Research, 7, 82-89.

[10] Chikazawa, S. and Sasaki, A. (2019) Literature Review Regarding Bathtime Incidents in Newborns and Infants. Journal of the Japan Maternal and Infant Care Association, 12, 83-90.

[11] Furuta, Y. (2016) Effects of Skin Cleansing Methods for Infants on Infants and Their Carers-Through Analyzing Three Different Methods. FPU Journal of Nursing Research, 13, 25-33.

[12] Kimu, A. and Hiramoto, I. (2013) Fact-Finding Survey on Bathing Methods for Children 18 Months of Age. Akita Journal of Maternal Health, 26, 44-48.

[13] Oikawa, Y., Miyata, H. and Shindo, Y. (2013) Preparation for Childbirth and Childcare among Women Expecting Her First Baby. Sonoda Women's College Studies, 47, 95-104.

[14] Tsuchihama, T., Usuda, M., Tanaka, Y. and Honda, S. (2011) Survey of Ablution of Newborns in the Home: The State of Facial Cleansing for the Prevention of Eczema in Infants. Kawasaki Municipal Hospital Internal Nursing Research Publication, 65, 5-7.

[15] Endo, T. (2009) Strategies Employed by Mothers of Twin Newborns during Ablution and Bathing. Japanese Nursing Association Collection, Community Nursing, 39, 57-59. 
[16] Ministry of Health, Labour, and Welfare of Japan (2020) Outline of 2019 Comprehensive Survey of Living Conditions. 6.

https://www.mhlw.go.jp/toukei/saikin/hw/k-tyosa/k-tyosa19/dl/02.pdf

[17] Kato, Y. (2015) Results of a Questionnaire on Accidents Involving Infants Aged 0-1 Year: Lack of Parent's Awareness on Dangers and Unexpected Infant Behaviors Are the Cause. Pediatric Maternal and Child Health, 74, 712-718.

[18] Wallis, B.A., Watt, K., Franklin, R.C., Nixon, J.W., et al. (2015) Where Children and Adolescents Drown in Queensland: A Population-Based Study. BMJ Open, 5, 26. https://doi.org/10.1136/bmjopen-2015-008959

[19] Sibert, J., John, N., Jenkins, D., et al. (2005) Drowning of Babies in Bath Seats: Do They Provide False Reassurance? Child: Care, Health and Development, 31, 255-259. https://doi.org/10.1111/j.1365-2214.2005.00516.x

[20] Ida, A., Kataoka, K. and Goda, N. (2013) A Survey on Internet Use by Child-Rearing Mothers: From the Results of a Questionnaire Answered by Mothers Who Participated in Municipal Programs Providing Child-Rearing Support. Maternal Health, 53, 427-436.

[21] Yagihashi, M. and Inaba, R. (2000) Studies on the Drowning Accidents of Infants in Home Bathtubs, in Gifu Prefecture. Acta Scholae Medicinalis Universitatis in Gi$f u, 48,155-165$. 